\title{
Evaluation of a commercial enzyme-linked immuno- sorbent assay (ELISA) kit for serological diagnosis of Helicobacter pylori infection in a group of non-ulcer dyspepsia sufferers
}

\author{
C.K. Ching, S. Thompson, C. Buxton, C. Holgate and G.K.T. Holmes \\ Departments of Medicine and Pathology, Derbyshire Royal Infirmary, London Road, Derby DEI 2QY, UK
}

\begin{abstract}
Summary: Helicobacter pylori infection of the stomach is associated with gastritis and peptic ulceration and may be causative. A noninvasive test for this organism might be useful in managing some patients with dyspepsia without the need for further investigation. We have evaluated a new commercially available serological test (Helico-G ${ }^{\mathrm{TM}}$ ELISA, Porton Cambridge, UK) for this infection to assess its diagnostic accuracy in a retrospective study of 115 patients with nonulcer dyspepsia. Sixty-three of these patients (55\%) were found to have $\mathrm{H}$. pylori infection and gastritis on histology. A sensitivity of $81 \%$ and specificity of $90 \%$ were obtained. No significant fall in the antibody titres was found in a subgroup of 15 patients who were selected to complete a course of triple therapy despite significant improvement in their dyspepsia score and confirmed eradication of $\boldsymbol{H}$. pylori organism in $80 \%$ of these patients. We conclude that the test has limited value in aiding clinical decision of managing patients with dyspepsia.
\end{abstract}

\section{Introduction}

The recent 'discovery' of Helicobacter pylori in association with peptic ulcer disease and non-ulcer dyspepsia ${ }^{1-3}$ has generated tremendous impetus in research at clinical as well as laboratory levels. The interest in this organism has largely been rekindled and pioneered by Warren and Marshall ${ }^{4,5}$ who demonstrated that this 'century old' microaerophilic spiral Gram-negative bacillus could account for chronic active gastritis as well as peptic ulcer disease. Their claim has since been substantiated by human volunteer and animals studies. ${ }^{6-9}$ A number of methods are currently available for detection of H. pylori infection ${ }^{10}$ (also see review ${ }^{2}$ ). Although the noninvasive tests (urea breath tests and enzymelinked immunosorbent assay (ELISA)) have recently received considerable attention, there are those who still prefer the gold standard tests of histology and microbiology ${ }^{2}$ to diagnose $H$. pylori infection. The urea breath tests are promising in diagnosis and follow-up but disadvantages are the requirement for a costly mass spectrometer and the potential danger with recurrent exposure to radioactivity.

Reports on the usefulness of ELISA as an alternative noninvasive diagnostic and screening

Correspondence: C.K. Ching, M.D., M.R.C.P., Medical Research Centre, City Hospital, Hucknall Road, Nottingham NG5 1PB, UK.

Accepted: 14 December 1992 test for $H$. pylori infection are encouraging. ${ }^{11-1}$ The majority of assays have employed bacteriaf extracts as antigens for detecting IgG antibody and show high sensitivity and specificity for diagnosis. Newell et al. ${ }^{12}$ developed the Helico-G ${ }^{\mathrm{TM}}$ ELISA and claimed sensitivity of $95.6 \%$ and specificity of $83 \%$ for their assay which has recently been marketed for aiding serological diagnosis of $H$. pylori. The same assay yielded sensitivity between 82 and $97 \%$ and specificity $87-100 \%$ in two recent studies. ${ }^{15,19}$ In this study, we aimed to evaluate the accuracy of this commercially available ELISA for serological diagnosis of $H$. pylori and compared the results with the conventional tests, histology and urea broth test.

\section{Materials and methods}

Confirmation of antral gastritis and $\mathrm{H}$. pylori infection

A retrospective analysis of 115 patients $(46$ males and 69 females; mean age of 38.5 years, range 19-53 years) with a final diagnosis of non-ulcer dyspepsia was performed in this study. None of these patients had received treatment other than antacids within 3 months of their endoscopy. $H$. pylori was detected by cytological brushing urea broth test and histology as described before. ${ }^{20}$ The 
presence of gastritis and the number of $H$. pylori organisms were similarly assessed as described previously. ${ }^{20}$ Serum was obtained from each patient and stored at $-20^{\circ} \mathrm{C}$ until required. Fifteen $H$. pylori-infected patients who had significant dyspepsia and elevated Helico-G titres were given a course of tripotassium dicitrato bismuthate ( $120 \mathrm{mg}$ four times daily) for 4 weeks, amoxycillin (500 $\mathrm{mg}$ three times daily) and metronidazole ( $400 \mathrm{mg}$ three times daily) for the first 10 days in an attempt to eradicate the organism. The dyspepsia scores, arbitrarily graded from 0 to $3(0=$ asymptomatic; 1 = mild dyspepsia; 2 = moderate dyspepsia; and 3 = severe dyspepsia) were recorded before and after treatment. Histology, cytological brushing urea broth test and the Helico-G titres were re-evaluated after 12 weeks.

\section{Enzyme-linked immunosorbent assay (ELISA)}

Helico-G ${ }^{\mathrm{TM}}$ ELISA is a commercially available test (Porton Cambridge, UK) for serological diagnosis of $H$. pylori. It contains micro-ELISA wells coated with acid glycine extracts of $H$. pylori surface proteins. It provides a quantitative analysis of the anti- $H$. pylori antibody titre that is present in patients' serum. The assay was performed on all the sera collected according to the manufacturer's instructions. The final results of the tested sera were expressed as $\mathrm{U} / \mathrm{ml}$ Helico-G titres with reference to the standards provided. The intraplate and interplate variation was assessed to check reproducibility of the test by repeating analysis of three $H$. pylori-positive and three $H$. pylori-negative patients' sera.

\section{Statistics}

Mann-Whitney $U$ test was used to assess the Helico-G antibody titres between the $H$. pylori positive and the $H$. pylori negative groups, the Helico-G titres and the number of $H$. pylori organisms present histologically in the $H$. pylori positive group. Furthermore it was also used to compare the dyspepsia scores and the Helico-G titres difference before and after triple medical therapy in the 15 selected patients. $P<0.05$ was accepted as a statistically significant result.

\section{Results}

Sixty-three out of the $115(55 \%)$ patients studied were found to be $H$. pylori positive by both the histology and cytological brushing urea broth test. Chronic atrophic gastritis with the presence of increased number of plasma cells and polymorphs infiltration was observed in all the $63(100 \%)$ $H$. pylori-positive patients. The remaining 52 patients showed negative cytological brushing urea broth test and normal histology without inflammation or $\boldsymbol{H}$. pylori organism.

The upper normal range of Helico-G titre was designated as $10 \mathrm{U} / \mathrm{ml}$ as recommended by the company. Elevated Helico-G titres were found in $51 / 63 \mathrm{H}$. pylori-positive (sensitivity $80.95 \%$ ) and $5 / 52 \mathrm{H}$. pylori-negative (specificity $90.38 \%$ ) patients (Figure 1 and Table I). The median Helico-G titre was $31.2 \mathrm{U} / \mathrm{ml}$ and $5.8 \mathrm{U} / \mathrm{ml}$ in the $H$. pylori-positive and the $H$.pylori-negative groups, respectively. The $H$. pylori-positive group had significantly higher Helico-G titres than the $H$. pylori-negative group $(P<0.0001)$. There was no correlation between the Helico-G titres and the number of $H$. pylori organisms present $(P>0.05)$. The mean $( \pm$ SEM) intraplate and interplate variation of the Helico-G ELISA was found to be $9.2 \%( \pm 3.3)$ and $14.8 \%$ ( \pm 3.8$)$, respectively.

Eleven out of the $15(73 \%)$ treated patients showed significant improvement in their mean dyspepsia score from 2.7 before treatment to 1.2 after treatment $(P<0.01)$. Three out of these 15

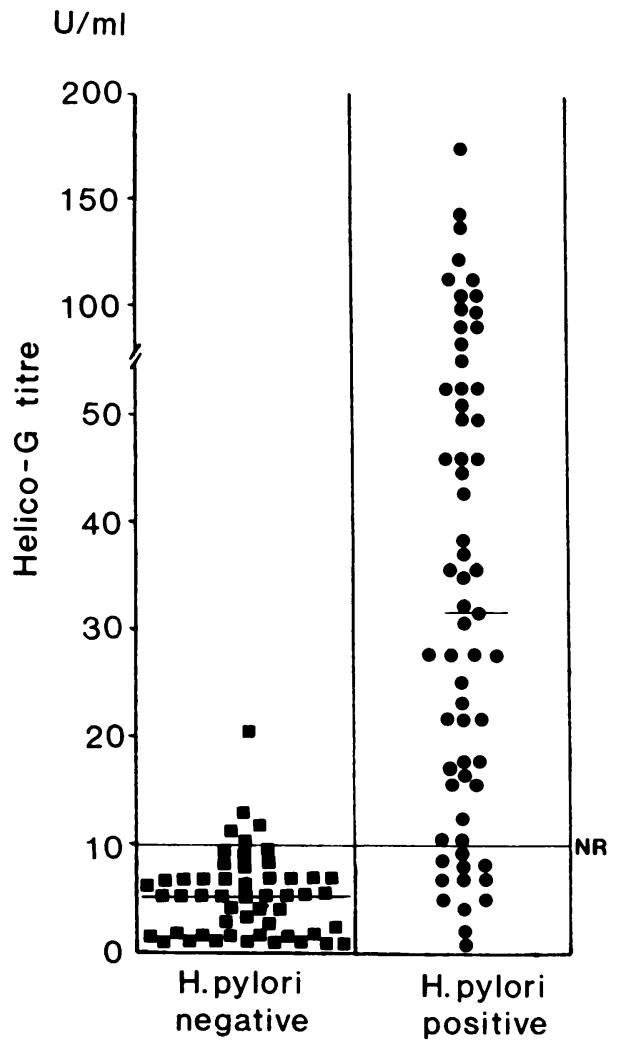

Figure 1 Scattergram of the Helico-G ELISA results (NR = normal range; $-\mathbf{-}-$ and $--=$ median Helico-G titres in the $H$. pylori-negative and $H$. pylori-positive group, respectively). 
Table I The results of the Helico-G ELISA

Sensitivity

Specificity

Positive predictive value

Negative predictive value

Efficiency

(20\%) patients remained $H$. pylori positive to cytological brushing urea broth test after triple medical therapy. These three patients demonstrated unchanged histological appearance of chronic atrophic gastritis with $H$. pylori scattered on the surface epithelium. The other 12 patients showed virtually normal gastric epithelium with minimal scattered submucosal fibrosis. $H$. pylori was not seen in these follow-up biopsy samples. Two out of three unresponded patients had largely unchanged Helico-G titres whereas the third demonstrated further elevation of the Helico-G titres (Figure 2). Only one out of the 12 patients who had eradication of $H$. pylori showed reduction of the Helico-G titre to the normal range (Figure 2). Overall, there was no significant difference in the Helico-G titres before and after triple therapy $(P>0.05)$.

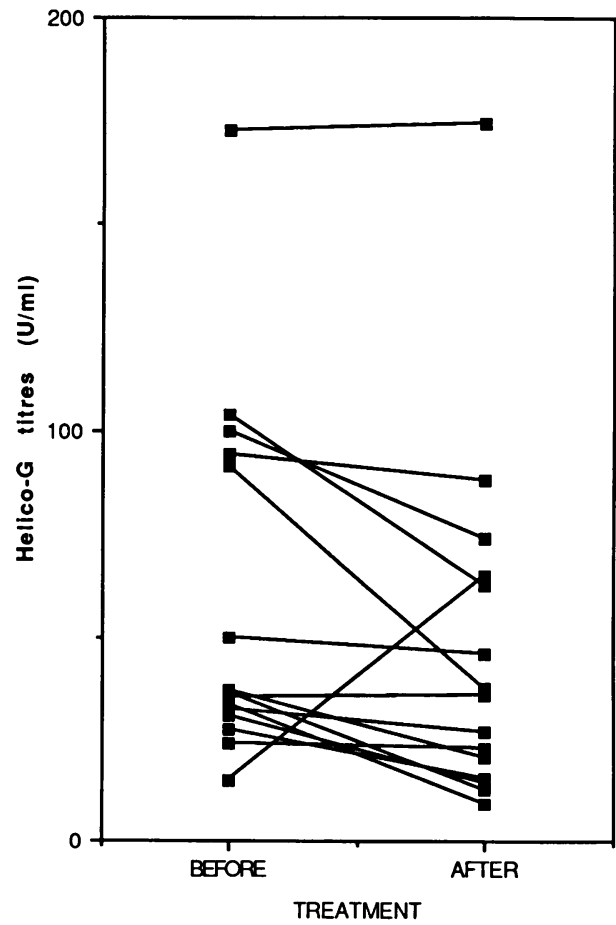

Figure 2 The Helico-G titres before and after triple medical therapy in the 15 selected patients.

\section{Discussion}

This study has shown that the commercially available Helico-G ${ }^{\mathrm{TM}}$ ELISA test has a reasonable sensitivity $(81 \%)$ and specificity $(90 \%)$ for detecting $H$. pylori infection serologically when the upper normal range is preset at $10 \mathrm{U} / \mathrm{ml}$ as recommended. However, the sensitivity falls short of the original report by Newell et al. ${ }^{12}$ and the company's quoted figure of $95 \%$. By using the recommended upper normal limit $(10 \mathrm{U} / \mathrm{ml})$ Logan et al. ${ }^{19}$ reported sensitivity $(82 \%)$ very similar to our current study. Sobala and colleagues ${ }^{15}$ reported a much higher sensitivity of $97 \%$. However, this was achieved by lowering the upper normal limit to $7.7 \mathrm{U} / \mathrm{ml}$. Even if the upper normal range were to be adjusted to yield specificity of $83 \%$ to match the original report $^{12}$ the sensitivity would merely improve to $84 \%$ in this study. Therefore, like Logan et al.$^{19}$ we were unable to reproduce the high sensitivity claimed by the company. Nevertheless, the test showed acceptable mean intraplate and interplate variation of $9 \%$ and $15 \%$, respectively.

ELISA for $H$. pylori infection has been advocated for use as a screening test in young dyspeptic patients who have no suspicion of underlying upper gastrointestinal tract malignancy. It was claimed that about one in four endoscopies mighto be avoided if the assay had been used as a screening test. ${ }^{14,15}$ However, the number of patients studies was small. Further prospective evaluation is required to support its role as a reliable screening tool before it is introduced into clinical practice.

In our study, the false negative rate was approximately $19 \%$ when $10 \mathrm{U} / \mathrm{ml}$ of Helico-G titre was chosen as the upper normal limit. Why we encountered such a high percentage of false negative results is unclear. It may be due either to the failure to seroconvert or poor antibody response in patients who have scanty bacterial colonization of the stomach as suggested previously. ${ }^{10}$ However, this was not borne out in this study as there was no correlation found between the number of $H$. pylori organisms present histologically and the Helico-G titres. In order to adopt ELISA as a screening tool for epidemiological surveys a much higher sensitivity is essential, approaching the results reported by Evans et al. (sensitivity $98.7 \%$ and specificity $100 \%) .{ }^{17}$ Otherwise, it would mean significant underestimation of the true prevalence of $H$. pylori-positive cases. The false positive rate in this study was approximately $10 \%$ which also is unacceptable if accurate epidemiological data is required.

Apart from its diagnostic and screening potential the ELISA for $H$. pylori infection has been claimed useful in monitoring response to medical therapy and predicting relapse. ${ }^{13,21-23}$ Our experience in a small subgroup of 15 patients who had 
received triple therapy and had antibody titres re-estimated after 12 weeks did not support such claims. Only a small proportion of these patients showed significant fall in Helico-G titres despite significant improvement in their symptoms, confirmed eradication of $H$. pylori and improvement in gastritis in the majority. The failure to demonstrate significant reduction in antibody titres in this study is unlikely to be attributed to the inadequacy of the Helico-G test. It may suggest a longer follow-up period is required to show the improvement. An extended study is underway to evaluate its role in monitoring patients' progress after combination therapy.

The link between $H$. pylori and duodenal ulcer disease is now widely accepted. However, the relationship between $H$. pylori and non-ulcer dyspepsia which has a prevalence range from $39 \%$ to $87 \%$ remains controversial. $H$. pylori infection has been found to be present in $55 \%$ of the patients with symptoms compatible with the diagnosis of non-ulcer dyspepsia. In this study, the presence of $H$. pylori correlated well with histo-

\section{References}

1. Axon, A.T.R. Campylobacter pylori. In: Pounder, R.E. (ed.) Recent Advances in Gastroenterology, Vol. 7. Churchill Livingstone, Edinburgh, 1988, pp. 225-244.

2. McKinlay, A.W., Upadhyay, R., Gemmell, C.G. \& Russell, R.I. Helicobacter pylori: bridging the credibility gap. Gut 1990, 31: 940-945.

3. Chamberlain, M.E. \& Peura, D.A. Campylobacter (Helicobacter) pylori. Is peptic disease a bacterial infection? Arch Intern Med 1990, 150: 951-955.

4. Warren, J.R. \& Marshall, B.J. Unidentified curved bacilli on gastric epithelium in active chronic gastritis. Lancet 1983, i: 1273-1275.

5. Marshall, B.J. \& Warren, J.R. Unidentified curved bacilli in the stomach of patients with gastritis and peptic ulceration. Lancet 1984, i: $1311-1314$.

6. Marshall, B.J., Armstrong, J.A., McGechie, D.B. \& Glancy, R.J. Attempt to fulfill Koch's postulates for pyloric campylobacter. Med J Aust 1985, 142: 436-439.

7. Morris, A. \& Nicholson, G. Ingestion of Campylobacter pyloridis causes gastritis and raised fasting gastric pH. $\mathrm{Am} \mathrm{J}$ Gastroenterol 1987, 82: 192-199.

8. Krakowka, S., Morgan, D.R., Kraft, W.G. \& Leunk, R.D. Establishment of gastric Campylobacter pylori infection in the neonatal gnotobiotic piglet. Infect Immun 1987, 55: 2789-2796.

9. Newell, D.G. Campylobacter pylori infections in non-human primates. In: Rathbone, B. \& Heatley, R.V. (eds) Campylobacter Pylori and Gastroduodenal Disease. Blackwell Scientific, Oxford, 1989, pp. 265-273.

10. Alpert, L.C., Graham, D.Y., Evans, D.J. et al. Diagnostic possibilities for Campylobacter pylori infection. Eur J Gastroenterol Hepatol 1989, 1: 17-26.

11. Kaldor, J., Tee, W., McCarthy, P., Watson, J. \& Dwyer, B. Immune response to Campylobacter pyloridis in patients with peptic ulceration. Lancet 1985, i: 921 .

12. Newell, D.G., Johnston, B.J., Ali, M.H. \& Reed, P.I. An enzyme-linked immunosorbent assay for the sero-diagnosis of Campylobacter pylori-associated gastritis. Scand J Gastroenterol 1988, 23 (Suppl 142): 53-57. logical gastritis which were both eliminated after successful treatment with triple therapy. This lends further support to the causal relationship between $H$. pylori infection and gastritis.

In conclusion, the Helico-G ELISA test lacks accuracy in our study. Furthermore, the results are disappointing when it is used to monitor patients' progress after attempted eradication therapy. However, the result may be very different if a longer follow-up period is allowed. Finally, gastritis due to $H$. pylori infection accounts for more than half of the final diagnosis in patients with non-ulcer dyspepsia. Triple medical therapy not only helps to eradicate $H$. pylori and improve histological gastritis but also improves patients' symptomatology. We feel that cytological brushing urea broth test and/or histological examination of gastric biopsies for the presence of gastritis and $H$. pylori infection should be carried out in patients with non-ulcer dyspepsia so that a positive diagnosis could be made and an appropriate remedy may be prescribed to help improve the patients' quality of life.

13. Van Bohemen, Ch.G., Langenberg, M.L., Rauws, E.A.J., Oudbier, J., Weterings, E. \& Zanen, H.C. Rapidly decreased serum IgG to Campylobacter pylori following elimination of Campylobacter in histological chronic biopsy in Campylobacter-positive gastritis. Immunol Lett 1989, 20: 59-62.

14. Loffeld, R.J.L.F., Stobberingh, E., Flendrig, J.A., van Spreeuwel, J.P. \& Arends, J.W. Diagnostic value of an immunoassay to detect anti-Clampylobacter pylori antibodies in non-ulcer dyspepsia. Lancet 1989, i: 1182-1185.

15. Sobala, G.M., Crabtree, J.E., Pentith, J.A. et al. Screening dyspepsia by serology to Helicobacter pylori. Lancet 1991, 338: 94-96.

16. Wyatt, J.I. \& Rathbone, B. The role of serology in the diagnosis of Campylobacter pylori infection. Scand J Gastroenterol 1989, 24 (Suppl. 160): 27-34.

17. Evans, D.J., Evans, D.G., Graham, D.Y. \& Klein, P.D. A sensitive and specific serologic test for detection of Campylobacter pylori infection. Gastroenterol 1989, 96: 1004-1008.

18. Crabtree, J.E., Shallcross, T.M., Wyatt, J.I. \& Heatley, R.V. Validation of a commercial ELISA for serodiagnosis of Helicobacter pylori infection. Gut 1990, 31: Al176.

19. Logan, R.P.H., Polson, R.J., Misiewicz, J.J. et al. Simplified single sample ${ }^{13}$ Carbon urea breath test for Helicobater pylori: comparison with histology, culture, and ELISA serology. Gut 1991, 32: 1461-1464.

20. Ching, C.K., Buxton, C., Holgate, C. \& Holmes, G.K.T. Cytological brushing urea broth test - A highly sensitive and specific test for Helicobacter pylori infection. Gastrointest Endosc 1991, 37: 550-551.

21. Von Wulffen, H. \& Grote, H.J. Enzyme-linked immunosorbent assay for detection of immunoglobulin $A$ and $G$ antibodies to Campylobacter pylori. Eur J Clin Microbiol Infect Dis 1988, 1: 559-565.

22. Vaira, D., Holton, J., Cairns, S.R. et al. Antibody titres to Campylobacter pylori after treatment for gastritis. $\mathrm{Br} \mathrm{Med} \mathrm{J}$ 1988, 297: 39. 
23. Veenendaal, R.A., Pena, A.S., Meijer, J.L. et al. Long term serological surveillance after treatment of Helicobacter pylori infection. Gut 1991, 32: 1291-1294.

24. Rokkas, T., Pursey, C., Uzoechina, E. et al. Non-ulcer dyspepsia and short term De-Nol therapy: a placebo controlled trial with particular reference to the role of Campylobacter pylori. Gut 1988, 29: 1386-1391.
25. Loffeld, R.J.L.F., Stobberingh, E., Flendrig, J.A. \& Arends, J.W. Presence of Helicobacter pylori in patients with nonulcer dyspepsia revealing normal antral histological characteristics. Digestion 1990, 47: 29-34. 